\title{
0 desafio da participação popular na construção e implementação da Política Estadual de Habitação de Interesse Social do estado da Bahia
}

\author{
Adriana Nogueira Vieira Lima
}

Universidade Estadual de Feira de Santana

\begin{abstract}
A evidência da crise de legitimação do modelo hegemônico de democracia que reduz o exercício do poder político à esfera estatal e ao desenho eleitoral impulsionou uma reflexão sobre a democracia na contemporaneidade. Partindo da crítica à democracia representativa, o texto busca contribuir para a reflexão sobre os limites e possibilidades do exercício da democracia participativa. Inicialmente apresenta os arranjos institucionais e práticas democráticas no Brasil, com foco nas políticas urbanas. Na parte subsequente, é feito um balanço do processo de construção da Política Estadual de Habitação de Interesse Social (Pehis) do estado da Bahia, no período 2006-11, apontando as ambiguidades e obstáculos da participação popular na sua construção e implementação.
\end{abstract}

Palavras-chave: direito à cidade; democracia participativa; administração pública; conselhos gestores; política de habitação de interesse social.

El desafío de la participación popular en el desarrollo e implementación de políticas de vivienda social en el estado de Bahía

La evidencia de la crisis de legitimidad del modelo hegemónico de democracia que reduce el ejercicio del poder político a la esfera estatal y el dibujo electoral provocó un debate sobre la democracia en el mundo contemporáneo. Al salir de la crítica de la democracia representativa, que pretende contribuir a la reflexión sobre los límites y las posibilidades del ejercicio de la democracia participativa. Inicialmente presenta los arreglos institucionales y las prácticas democráticas en Brasil, centrado en las políticas urbanas. En la parte posterior se hace un columpio para la construcción de Vivienda de Interés Social Política del Estado de Bahía, en el período 2006-11 el proceso, señalando las ambigüedades y los obstáculos de la participación popular en su diseño e implementación.

Palabras clave: derecho a la ciudad; poder local; democracia participativa; administración pública; política de vivienda social.

DOI: http://dx.doi.org/10.1590/0034-76121600

Artigo recebido em 12 jun. 2013 e aceito em 24 jul. 2014.

Rev. Adm. Pública - Rio de Janeiro 48(6):1431-1450, nov./dez. 2014 
The challenge of popular participation in the development and implementation of the policy for social housing in the state of Bahia

The evidence of the legitimation crisis regarding the hegemonic model of democracy that reduces the exercise of political power to the state sphere and to elections has led to a reflection about contemporary democracy. From the criticism to the representative democracy, the aim of this text is to contribute to the reflection on the limits and possibilities of exercising participative democracy. The author begins by presenting institutional arrangements and democratic practices in Brazil, focusing on urban policies. Next, the author assesses the process of developing Social Housing Policy in the State of Bahia (Pehis), especially during the period of 2006 to 2011,highlightingthe ambiguities and obstacles to popular participation in its development and implementation.

KeYwords: right to the city; participative democracy; public administration; public policy council; social housing policy.

\section{Introdução}

A concepção hegemônica de democracia que restringe a prática democrática ao conjunto de regras de procedimentos para a formação de decisões coletivas, obtidas através do sufrágio universal, e, portanto, restrita ao modelo de representação, nos termos definidos por Bobbio (1986), vem passando por uma crise de legitimidade. Para Safatle (2012), essa crise pode ser evidenciada no esgotamento do modelo de democracia parlamentar liberal, no qual as pessoas não se sentem mais representadas e passam a manifestar-se de diversas formas, exigindo uma democracia real que perpasse pelo transbordamento da política da esfera estatal e valorização da soberania popular. No campo também da crítica aos processos representativos, Chauí (1993) chama a atenção para a necessidade do exercício de outra democracia que passe pela afirmação e criação de direitos, através da construção dos sujeitos sociopolíticos por sua própria ação, ultrapassando o sentido restrito da cidadania como voz e voto.

Nesse sentido, Sousa Santos e Avritzer (2002) propõem uma democracia contra-hegemônica, na qual os novos sujeitos sociais passam a reivindicar o direito de organizar-se politicamente e participar das decisões, propondo a quebra do monopólio do Estado como único detentor de poder e espaço público. É justamente a articulação entre democracia representativa e participativa, por meio da ampliação do experimentalismo democrático (novas gramáticas sociais), que poderá, segundo o autor, ampliar a diversidade cultural e social.

No Brasil, partindo da premissa de que o processo eleitoral não esgota os procedimentos de autorização do cidadão, podendo a soberania ser exercida também através de forma direta de participação, a Constituição Federal de 1988 prevê a compatibilização entre os mecanismos de democracia representativa e democracia direta, sendo estabelecido no parágrafo único do art. $1^{\circ}$ que "todo poder emana do povo que o exerce por meio de seus representantes eleitos ou diretamente, nos termos desta Constituição".

O texto constitucional é resultado da pressão de diversas forças populares que buscaram estabelecer um novo padrão de política pública e reforma democrática do Estado que fosse ca- 
paz de assegurar o reconhecimento de direitos. Segundo Gonh (2012), os movimentos sociais passaram a redefinir a esfera pública, redefinindo também a relação entre Estado e sociedade. Nesse contexto, é importante destacar o papel do movimento da Reforma Sanitária, fundado na utopia democrática igualitária, que culminou na inscrição do direito universal à saúde na carta constitucional (Fleury, 1997), e do movimento da Reforma Urbana, cujos pilares foram institucionalizados também no texto constitucional (Grazia, 2002).

No campo da divisão de poderes e competências entre os entes federados, segundo Trevas (2012), com a promulgação da Constituição de 1988, houve um redesenho do pacto federativo. Essa arquitetura, ainda segundo o autor, teve, como centralidade, a questão democrática alicerçada na cidadania e na afirmação de direitos e estabeleceu, com nitidez, uma relação entre democracia e Federação, com o aprofundamento da descentralização política e afirmação do município como ente federado.

Essa combinação possibilitou inovações democráticas no período pós-Constituição de 1988 e a proliferação de espaços participativos, que representaram uma possibilidade do exercício da cidadania tanto no sentido de controle social do Estado como de interlocução entre o Estado e a sociedade, tendo em vista o estabelecimento de diretrizes para ação pública, através das conferências, orçamentos participativos, conselhos gestores de políticas públicas, entre outros.

Na esfera local, houve uma forte mobilização da sociedade civil para elaboração das Leis Orgânicas Municipais que incorporam mecanismos de participação e controle social. Também nessa esfera são experimentadas práticas participativas inovadoras, a exemplo do Orçamento Participativo, em 1989, na cidade de Porto Alegre, capital do estado do Rio Grande do Sul. Por esse instrumento, na visão de Avritzer (2002), busca-se o envolvimento da população para tomada de decisão na aplicação de verbas públicas, de modo a reverter as prioridades de distribuição de recursos públicos e realizar políticas redistributivas. Esse modelo de participação, segundo Sintomer e colaboradores (2012), foi considerado um exemplo de boa governança e distribuição dos recursos públicos, sendo difundido por diversos municípios brasileiros, atingindo, no ano de 2010, cerca de 250 experiências, servindo também como inspiração para outros países da América Latina, como o Equador, Peru, Argentina e Uruguai.

Os conselhos gestores de políticas, conceituados por Gohn (2011:7) como "canais de participação que articulam representantes da população e membro do poder público estatal em práticas que dizem respeito à gestão de bens públicos", também estão sendo intensamente experimentados nas esferas federal, estadual e municipal, podendo ser encontrada uma vasta literatura sobre o assunto (Ipea, 2013; Polis/Inesc, 2011; Gohn, 2011; Pontual, 2008; Tatagiba, 2002). No âmbito federal, segundo dados dispostos no sítio oficial da Secretaria Nacional de Articulação Social da Presidência da República (Brasil, 2014), existem atualmente 40 Conselhos de Políticas Públicas Nacionais, sendo 19 criados entre 2003-13. Também é possível notar a influência das novas abordagens em torno da temática de raça, gênero, faixa etária e etnia, através da criação do Conselho Nacional do Idoso (em 2002), Conselho Nacional da Juventude (em 2005), Conselho Nacional da Promoção da Igualdade Racial (em 2003), entre outros. 
A proliferação de conselhos gestores de políticas públicas também pode ser notada na esfera local. Segundo Pesquisa de Informações Básicas Municipais (IBGE, 2009), existiam em 2009, no Brasil, 43.156 conselhos municipais, envolvendo diversos eixos das políticas públicas. A frequência dos conselhos nos municípios sofre grande variação em função da temática, havendo uma maior incidência nas áreas de assistência social, educação e saúde, conforme disposto na tabela 1 .

Tabela 1

Número de conselho por política setorial, e percentual relativo ao total de municípios - Brasil 2011

\begin{tabular}{|cccccc|}
\hline Áreas & Municípios & $\%$ & Áreas & Municípios & $\%$ \\
\hline Criança e & 5.447 & $97,8 \%$ & Educação & 4.718 & $84,7 \%$ \\
Adolescente & & & Conselho Tutelar & 5.522 & $99,2 \%$ \\
Saúde & 5.553 & $99,7 \%$ & 195 & $3,5 \%$ \\
Política Urbana & 1.231 & $22,1 \%$ & Saneamento & 2.868 & $51,5 \%$ \\
Direitos da Mulher & 872 & $15,7 \%$ & Idoso & & \\
\hline
\end{tabular}

Fonte: IBGE (2012).

Total de Municípios no Brasil: 5.565, até 31-12-2011.

Outro instrumento de interação entre o Estado e a sociedade, que vem sendo amplamente experimentado no Brasil, são as conferências, que, segundo Souza e colaboradores (2013:26), são "processos participativos de interlocução entre Estado e sociedade, convocados pelo Poder Executivo e desenvolvidos em etapas interconectadas a partir da escolha de representantes e da formulação de propostas para políticas públicas". Assim, como ocorreu em relação aos demais arranjos participativos, é possível notar, nos últimos anos, uma intensificação do uso desses espaços. Das 139 conferências nacionais realizadas entre o período de 1941 a 2013, 97 aconteceram entre 2003 e 2013 (Brasil, 2014), envolvendo, segundo Avritzer (2012), no período de 2003-10, 6,5\% da população brasileira.

Se, por um lado, é inegável reconhecer que houve uma forte mudança na cultura política e uma ressignificação do conceito de democracia no Brasil, contribuindo, segundo Dagnino, Olvera e Panfichi (2006), para uma desprivatização do Estado, tornando-o mais permeável ao interesse público formulado nas instâncias de participação da sociedade, por outro, esse projeto sofre limites advindos "dos compromissos eleitorais feitos para governar, falta de recursos provocada pelos 'ajustes' que impedem políticas sociais redistributivas, as prioridades impostas pela condução neoliberal da economia e o crescente poder das capacidades técnicas exigidas para conduzir o Estado" (Dagnino, Olvera e Panfichi 2006:77).

É nesse contexto mais amplo de análise dos dilemas da democracia participativa que o presente trabalho está inserido. Para tanto, busca contribuir com a avalição dos limites e avanços da democracia participativa, tomando, como estudo de caso, o processo de construção e implementação da Política Estadual de Habitação de Interesse Social (Pehis) e do Sistema 
Estadual de Habitação de Interesse Social (Sehis) no estado da Bahia, analisando o período de 2006-11.

Alguns pressupostos analíticos guiaram a concepção deste trabalho: a) houve um avanço na institucionalização de instâncias de participação e controle social após a promulgação da Constituição Federal de 1988; b) há uma forte indução do governo federal na criação dos arranjos participativos, na esfera local, no campo das políticas urbanas, notadamente após a criação do Ministério das Cidades em 2003; c) o amplo processo de participação social para a construção da Pehis, embora tenha representado uma mudança na cultura política do estado da Bahia, não garantiu, por si só, um efetivo poder decisório dos movimentos de luta pela moradia, na sua implementação.

Em termos metodológicos, este artigo foi conduzido pela pesquisa qualitativa. O primeiro contato com o objeto da pesquisa ocorreu entre 2005-06, em função da contratação da autora, pela Secretaria de Desenvolvimento Urbano do Estado da Bahia (Sedur), para integrar a equipe de consultoria para elaboração de estudos técnicos, visando subsidiar a elaboração da Pehis. Em um segundo momento, compreendido entre 2006-10, a autora atuou na diretoria da Sedur, sendo designada para compor o Grupo de Trabalho criado para promover o acompanhamento e sistematização das discussões da Pehis.

A investigação também apoiou-se em uma vasta pesquisa às fontes primárias, sendo analisados textos normativos, atas de reuniões do Conselho Estadual das Cidades/Bahia e do Conselho Gestor do Fundo Estadual de Habitação de Interesse Social do Estado da Bahia (CGFEHIS) realizadas entre 2009-11, ${ }^{1}$ documentos técnicos (Bahia, 2006, 2006a) e relatórios de gestão (Bahia, 2012, 2013).

Embora diversos estudos de caso analisem a trajetória do funcionamento dos conselhos gestores, abarcando diferentes contextos no país, ainda são escassas as investigações com foco nos arranjos institucionais criados no bojo do Sistema Nacional de Habitação de Interesse Social (SNHIS), principalmente com o foco na Região Nordeste, que, segundo dados da Fundação João Pinheiro (2013), acumula, em termos absolutos, 30\% do déficit habitacional do país.

Seguindo esta introdução, o artigo está estruturado em duas partes. Na primeira, é feita um breve balanço dos arranjos institucionais que buscaram operacionalizar as inovações democráticas no período que se segue à promulgação da Constituição de 1988, com foco na política urbana. Na segunda parte, analisa o processo de construção da Pehis, identificando os principais sujeitos que atuaram na sua construção, as estratégias de mobilização e as instâncias de participação. Nessa parte, também é feito um balanço do funcionamento do Fehis e do conselho gestor.

\footnotetext{
${ }^{1}$ Foram analisadas as Atas de reuniões do Conselho Estadual das Cidades realizadas nos dias 19 jun. $2009 ; 14$ dez. 2009; 21 ago. 2009; 31 set. 2009; 13 nov. 2009; 4 mar. 2010; 4 maio 2010; 15 out. 2011; 10 dez. $2010 ; 21$ jul. 2011 ; 18 mar. 2011; 19 maio 2011; 23 set. 2011; 20 out. 2011; e as Atas de reuniões do CGFEHIS realizadas nos dias 20 ago. 2009; 24 nov. 2009; 30 nov. 2009; 15 dez. 2009; 18 ago. 2010; 23 nov. 2010;16 jun. 2011 e 21 jul. 2011.
} 


\section{A institucionalização dos arranjos democráticos no campo da política urbana}

No início da década de 1980, a ditadura militar começa a dar sinais de enfraquecimento, e o movimento social passa a buscar a redemocratização do Estado brasileiro por meio da modificação da institucionalidade vigente, como visto neste trabalho. No campo das lutas urbanas, é recolocada em pauta a reivindicação do direito à cidade que, no dizer de Lefebvre (1991), é o resultado do direito à vida humana, condição de um humanismo e de uma democracia renovados. Atualizando esse conceito, Harvey (2012) afirma que o direito à cidade não é o direito do que já existe na cidade, mas o direito de todos de transformarem a cidade em algo radicalmente diferente, através de um poder coletivo sobre os processos de urbanização de modo a construir diferentes tipos de cidade que satisfaçam as necessidades humanas. Na busca desse ideal, o movimento pela reforma urbana passou a intervir no processo de construção de uma Nova Ordem Constitucional, visando assegurar a inscrição de direitos econômicos, políticos, sociais e culturais, sendo apresentada a proposta popular da Reforma Urbana, subscrita por $131 \mathrm{mil}$ brasileiros, que resultou na inscrição do Capítulo da Política Urbana na Constituição Federal.

Apesar da ausência de normas infraconstitucionais regulamentadoras desses artigos, durante a década de 1990, diversas reivindicações pautadas pelo Movimento da Reforma Urbana puderam ser experimentadas. Segundo Bitoun (2010), as problemáticas visibilizadas pelos movimentos sociais de base territorial pressionaram para que fossem inventadas soluções inéditas que não poderiam ser encontradas no acervo daquelas acumuladas nas legislações urbanas dos países do Norte. Nessa esfera, podem ser destacados a elaboração de planos diretores municipais participativos, a criação do Fundo Municipal de Habitação Popular e do Conselho Municipal de Habitação Popular, nos municípios de Diadema (SP) - 1993, Belo Horizonte (MG) - 1993 e Santo André (SP) — 1999, e o estabelecimento das Zonas Especiais de Interesse Social em Recife (PE) e Salvador (BA), em 1985.

A partir dessas experiências e após mais de uma década da promulgação do texto constitucional, é aprovada a Lei Federal no 10.257, de 10 de julho de 2001, denominada Estatuto da Cidade, regulamentando os artigos 182 e 183 da Constituição Federal de 1988 (Brasil, 2001). Esse marco normativo representou um terreno fértil para o fortalecimento das reivindicações e utopias voltadas para o cumprimento da função social da propriedade e abertura de canais de participação no processo de planejamento da cidade.

Com a eleição do presidente Lula em 2002, representando forças de centro-esquerda, foi criado o Ministério das Cidades, que buscou trazer, para o plano nacional, o acúmulo dessas experiências. Os militantes que estavam nas trincheiras da luta fora do Estado ou participaram das administrações municipais passaram a fazer parte da burocracia pública federal, podendo ser constatados um recrudescimento da luta pela reforma urbana, através do viés institucional, e uma conversão ao sistema político institucional.

O Ministério das Cidades passou a estruturar novos arranjos institucionais e abrir canais de participação através das Conferências da Cidade e do Conselho Nacional das Cidades. Na visão de Maricato (2006), a criação dessas esferas de participação representou uma conquista do movimento pela Reforma Urbana e um grande potencial na construção de uma esfera pú- 
blica de concertação entre os diferentes atores, em que foi possível emergirem conflitos que sempre foram sufocados pela tradição política brasileira.

A $1^{\text {a }}$ Conferência Nacional das Cidades, realizada em 2003, reuniu 2,5 mil delegados dos 27 estados e teve como lema "Cidade para Todos" e como tema "Construindo uma política democrática e integrada para as cidades", sendo discutidos os princípios e objetivos da Política Nacional de Desenvolvimento Urbano e Política de Habitação. Nela também foram eleitos os membros do Conselho Nacional das Cidades, órgão deliberativo e consultivo, integrante da estrutura do Ministério das Cidades, composto por 86 titulares, sendo 49 representantes de segmentos da sociedade civil e 37 dos poderes públicos federal, estadual e municipal. A $2^{\text {a }}$ Conferência (2005) teve participação de 1.820 delegados, teve como lema "Reforma urbana: cidade para todos" e como tema "Construindo uma política nacional de desenvolvimento urbano". A 3 a Conferência Nacional das Cidades (2007) teve como lema "Desenvolvimento urbano com participação popular e justiça social" e o tema "Avançando na gestão democrática das cidades". Durante a $4^{\text {a }}$ Conferência Nacional das Cidades (2010), houve a discussão em torno do lema "Cidade para todos e todas com gestão democrática participativa e controle social".

Com base nas deliberações da 1aㅡ Conferência Nacional, foi estruturada a Política Nacional de Habitação (PNH), tendo como principais componentes a integração urbana de assentamentos precários, a urbanização, a regularização fundiária e a inserção de assentamentos precários, a provisão da habitação e a integração da política de habitação à política de desenvolvimento urbano (Brasil, 2004). Por fim, foi aprovada a Lei Federal no 11.124, de 16 de junho de 2005, que dispõe sobre o SNHIS, cria o Fundo Nacional de Habitação de Interesse Social (FNHIS) e institui o Conselho Gestor do Fundo Nacional de Habitação de Interesse Social (CGFNHIS) (Brasil, 2005). Esse marco normativo tem origem no Projeto de Lei de iniciativa popular no 2.710 , de 8 de abril de 1992, subscrito por um milhão de assinaturas e patrocinado por entidades do Fórum Nacional da Reforma Urbana, com respaldo no art. 61 da Constituição Federal, que dispõe sobre a iniciativa popular de projeto de lei.

O SNHIS tem como função articular as políticas de habitação social de forma descentralizada e democrática, respaldado no desenho constitucional traçado para o pacto federativo brasileiro e no princípio da cooperação entre os entes federados, tendo como objetivo principal "viabilizar para a população de menor renda o acesso à terra urbanizada e à habitação digna sustentável" (Brasil, 2005). Para tanto, são estabelecidos, como mecanismos de gestão participativa, o FNHIS e seu Conselho Gestor (Brasil, 2005).

A criação do SNHIS proporcionou uma arquitetura capaz de permitir, ainda que em tese, uma divisão compartilhada de atribuições entre os entes federados, na esfera da competência constitucional comum de produção de habitação. Os estados e municípios passaram a aderir ao SNHIS a partir da assinatura do termo de adesão, assumindo, na ocasião, o compromisso de criar os sistemas e os planos locais de habitação de interesse social. Os sistemas devem ter necessariamente um fundo com dotação orçamentária específica gerido por um conselho com a participação paritária entre os membros do poder público e da sociedade civil, sob pena de ficarem impedidos de acessar os recursos do FNHIS.

A criação do SNHIS teve um impacto sobre os governos locais na institucionalização dos conselhos e fundo de habitação, considerando que, segundo Arretche (2012), até 2005, ape- 
nas $17 \%$ e $15 \%$ dos municípios haviam instalado respectivamente os conselhos e fundos de habitação, passando, em 2011, nos termos da tabela 2, respetivamente para 68,2\% e 71,7\%. É nesse sentido que Inês Magalhães (2012:3), secretária nacional de habitação desde 2004, aduz que "o governo federal, emprega a sua autoridade para regular e seu poder de gasto para induzir a criação de capacidades administrativas no plano local" (grifos nossos).

Tabela 2

Municípios com termos de adesão ao SNHIS, Conselho/ Fundo Gestor de FHIS e PLHIS (2006-11)

\begin{tabular}{|lrl|}
\hline Termo de adesão ao SNHIS & 5.392 & $96,8 \%$ \\
Fundo de Habitação de Interesse Social & 3.989 & $71,7 \%$ \\
Conselho Gestor do FHIS & 3.797 & $68,2 \%$ \\
PLHIS & 633 & $11,4 \%$ \\
\hline
\end{tabular}

Fonte: IBGE, 2012

Total de Municípios no Brasil: 5.565, até 31-12-2011.

\section{A participação popular na construção da Política de Habitação de Interesse Social do estado da Bahia}

\subsection{Atores, mobilização e arranjos participativos na construção da Pehis}

O estado da Bahia acumula o déficit habitacional de 521.374 unidades habitacionais, ocupando, em números absolutos, o primeiro lugar na Região Nordeste, e o terceiro, no Brasil (Fundação João Pinheiro, 2013). No intuito de enfrentar essa problemática e considerando as exigências contidas para adesão ao SNHIS, foram contratados estudos para lastrear a elaboração da Pehis.

Embora a participação social não fosse propriamente considerada como método de gestão, os estudos foram discutidos no Seminário "Notas técnicas da Pehis", realizado em maio de 2006, em que o caráter técnico administrativo foi ampliado para a participação de setores da sociedade civil, notadamente representantes de luta pela moradia urbana, sendo, ao final dessa etapa, elaborado o anteprojeto de Lei da Pehis. Em 2006, apesar da mudança de gestão governamental, sendo eleito um representante oriundo do Partido dos Trabalhadores, não houve descontinuidade do processo de construção da Pehis. Nessa ocasião, em virtude de o Conselho Estadual das Cidades ainda não existir e no intuito de ampliar o processo de participação social, foi constituído um Grupo de Trabalho, pelo Decreto Estadual no 10.366, de 31 de maio de 2007, com a atribuição de acompanhar e sistematizar a discussão do anteprojeto de Lei da Pehis (Bahia, 2007c).

A composição do Grupo de Trabalho guardava a proporcionalidade do Conselho Nacional das Cidades, integrado por representantes do poder público e sociedade civil, sendo três representantes do segmento dos trabalhadores e entidades sindicais, três representantes do segmento empresarial, nove representantes do segmento movimento social e popular, dois 
representantes do segmento de organizações não governamentais, dois representantes do segmento das entidades profissionais, acadêmicas e de pesquisa, sete representantes do segmento poder público municipal, dois representantes do segmento poder público federal e cinco representantes do segmento poder público estadual (Bahia, 2007b). No que tange ao perfil dos representantes do segmento popular e social, foram agregados, aos representantes das entidades de luta pela moradia que tradicionalmente participam desses espaços, ${ }^{2}$ os articuladores dos territórios de identidade e representantes de sindicatos de trabalhadores rurais.

O Grupo de Trabalho, por meio de seus representantes, contribuiu com a elaboração do regimento interno das audiências (Bahia, 2007a), definição das cidades-sedes, mobilização dos diversos setores da sociedade civil. Também coube a esse grupo acompanhar a discussão do anteprojeto de Lei da Pehis nas 14 audiências públicas que ocorreram entre os meses de junho, julho e agosto de 2007, tomando como base os 27 Territórios de Identidade existentes no estado da Bahia, conforme espacializado na figura 1.

As audiências públicas foram precedidas de um amplo processo de mobilização e divulgação por meio de jornais de circulação, cartas-convites, rádios locais, distribuição de cartilhas, carros de som e faixas, grupos de teatro. Esse esforço resultou na participação de cerca de 3 mil pessoas, ${ }^{3}$ oriundas de diferentes matizes social, econômico e cultural: comunidades quilombolas, comunidades ribeirinhas, comunidades de fundo de pastos, ${ }^{4}$ ciganos, marisqueiras, pescadores, índios, terreiros de candomblé, comunidades eclesiais de base da Igreja Católica, evangélicos, comerciantes, estudantes, professores, deputados, vereadores, servidores públicos, sem-teto, sem-terra, assentados da reforma agrária, sindicatos de trabalhadores rurais, sindicato da indústria da construção civil, artistas.

Durante os debates realizados, foi possível perceber não apenas as reivindicações de cunho geral, que versavam sobre o estabelecimento dos mecanismos de controle social, critérios para a participação nas instâncias participativas e fontes de receitas para a garantia de fluxo contínuo para habitação de interesse social, mas também aquelas pautadas nas singularidades dos grupos presentes e nas particularidades dos territórios de identidade do estado da Bahia. As discussões afloradas apontaram para a necessidade de fixar critérios para definição de quotas e priorizações que abarcassem as dimensões de raça, gênero, pessoas com deficiência, faixa etária e comunidades tradicionais. As pautas relativas aos moradores de áreas rurais também foram sendo afloradas. Durante todas as audiências públicas, os representantes de sindicatos de trabalhadores, associações de pequenos produtores e articuladores dos territórios procuraram destacar a importância da habitação rural, bem como a necessidade da sua articulação com temas afetos à reforma agrária e à função social da propriedade rural.

\footnotetext{
${ }^{2}$ Confederação Nacional das Associações de Moradores (Conam), União Nacional de Moradia Popular (UNMP), Movimento Nacional de Luta pela Moradia (MNLM), Central de Movimentos Populares (CMP), Frente de Luta por Moradia (FLM), Movimento Sem-Teto de Salvador (MSTS/MSTB), Movimento Luta pela Terra (MLT).

${ }^{3}$ Durante as audiências públicas também foi discutido o anteprojeto de Lei que deu origem à Lei no 10.704 , de 12 de novembro de 2006, que institui o Conselho Estadual das Cidades.

${ }^{4}$ Fundos de Pastos é uma forma tradicional de uso coletivo da propriedade rural que pode ser observada no Semiárido baiano (Torres, 2011).
} 


\section{Audiências públicas para discussão da Pehis}

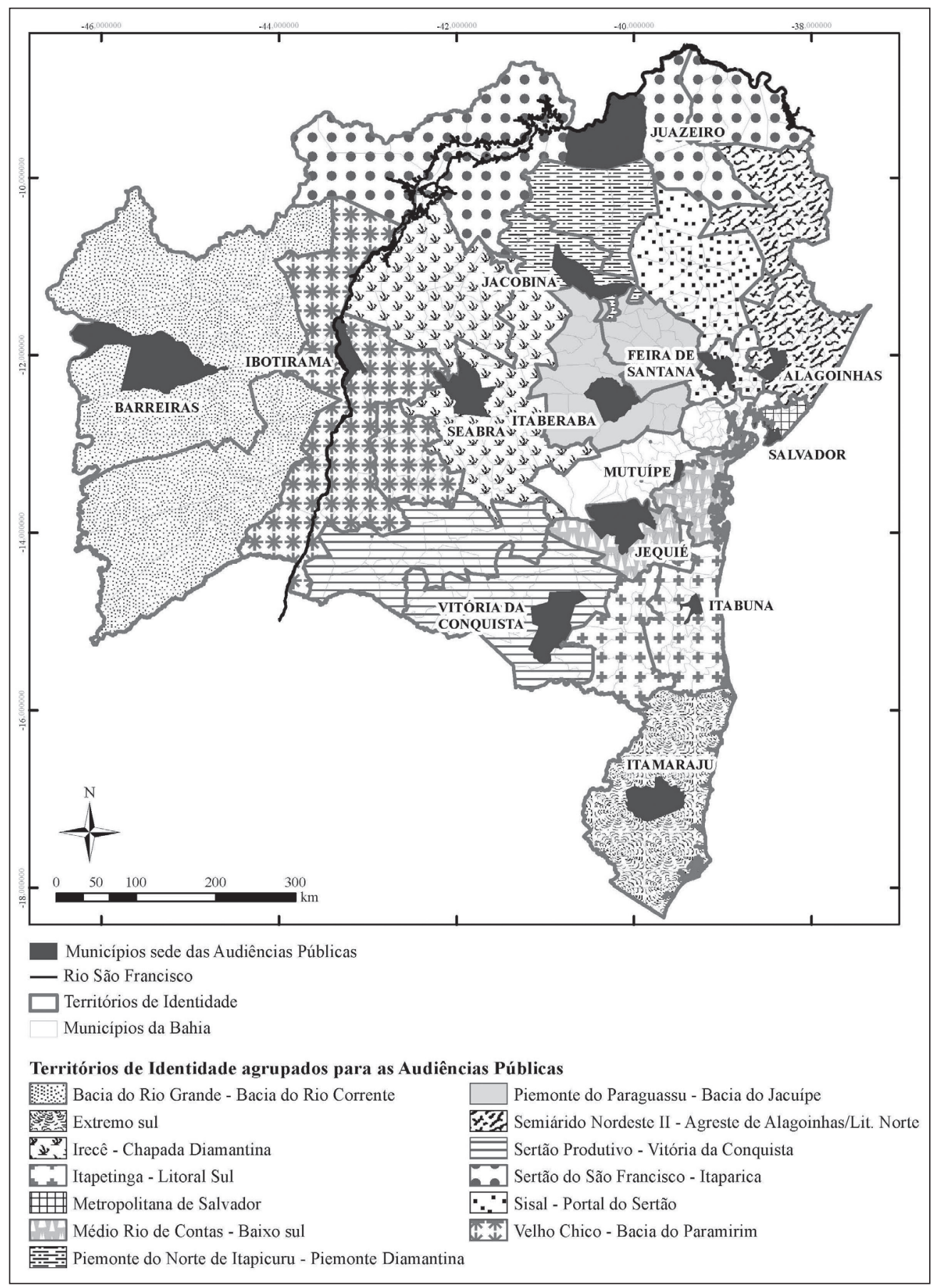

Fonte: Bahia (2007). Elaboração própria. 
Nessa etapa do trabalho, foi possível observar, na condição de membro do Grupo de Trabalho e acompanhamento da Pehis, que as controvérsias apontadas nas audiências públicas foram sendo pactuadas entre os membros do Grupo de Trabalho, subsistindo, entretanto, divergência entre os representantes dos movimentos de luta pela moradia e setores específicos do governo (Casa Civil, Secretaria da Fazenda e Secretaria de Desenvolvimento Social e Combate a Pobreza $)^{5}$ em relação à destinação de recursos de forma mais detalhada e vinculados ao Fundo Estadual de Habitação de Interesse Social (Fehis), a exemplo do estabelecimento de percentual mínimo do montante dos recursos destinados ao Fundo de Combate e Erradicação da Pobreza. Embora essa divergência fosse explicitada nas reuniões do Grupo de Trabalho, em última instância, esse assunto foi tratado em reuniões específicas com a presença apenas de gestores governamentais, sendo acatada a decisão por parte do movimento social que compunha o Grupo de Trabalho, em nome da governabilidade e da confiança estabelecida em relação ao novo governo.

Esse processo culminou com o envio do Projeto de Lei no 17.007, de 12 de dezembro de 2007, à Assembleia Legislativa do Estado da Bahia. Nessa esfera de poder, houve uma emenda parlamentar, oriunda da bancada de oposição, com objetivo de restringir o dispositivo que permitia o acesso das fundações, associações comunitárias e cooperativas habitacionais aos recursos do Fehis. Essa proposta deflagrou um processo de mobilização dos movimentos de luta pela moradia do estado da Bahia e articulações por parte do governo que resultaram na aprovação, por unanimidade, pela Assembleia Legislativa do Estado, do Projeto de Lei, nos termos enviados pelo chefe do Poder Executivo Estadual, sendo rejeitada a emenda da bancada de oposição.

\subsection{Princípios, diretrizes e arranjos participativos da Pehis}

A Lei Estadual no 11.041, de 7 de maio de 2008, que instituiu a Política e o Sistema Estadual de Habitação de Interesse Social e criou o Fundo Estadual de Interesse Social, tem a finalidade de orientar planos, programas, projetos e ações dos órgãos e entidades que compõem o Sehis, de modo a proporcionar moradia digna à população de baixa renda, conceituada como "população urbana ou rural sem renda ou com renda familiar mensal equivalente a até três salários mínimos vigentes" (Bahia, 2008). Nela estão contidos princípios, diretrizes e instrumentos destinados à execução da Política de Habitação de Interesse Social, podendo ser destacadas diretrizes específicas para as comunidades tradicionais, instrumentos jurídicos e procedimentos voltados para a mediação de conflitos fundiários, procedimentos e instrumentos para utilização dos bens públicos e descentralização de poderes para esfera local e repasse de recursos, mediante convênios, para entidades que desempenhem atividades na área de habitação de interesse social.

\footnotetext{
${ }^{5}$ A gestão do Fundo Estadual de Combate e Erradicação da Pobreza esteve vinculada à Secretaria de Desenvolvimento Social e Combate a Pobreza, sendo apenas em 2009 transferida para a Casa Civil.
} 
A criação do Sehis também representou um marco importante para dar início à articulação das ações voltadas à habitação de interesse social, que vinham sendo realizadas de forma fragmentada dentro da estrutura do estado, através da Secretaria de Desenvolvimento Urbano (Sedur), Companhia de Desenvolvimento do Estado (Conder), Secretaria de Combate à Pobreza (Secomp), atualmente denominada de Secretaria de Desenvolvimento Social (Sedes), e Companhia de Desenvolvimento e Ação Regional (CAR).

Seguindo o modelo do SNHIS, a Lei Estadual no 11.041, de 7 de maio de 2008, regulamentada através do Decreto ํㅡㄴ 11.539, de 15 de maio de 2009, prevê o Fehis e seu conselho gestor (Bahia, 2009a). Nela está previsto que o Fehis centralizará todos os recursos orçamentários destinados à execução dos programas de habitação de interesse social, devendo sua execução estar submetida aos princípios e diretrizes contidos na Pehis e nas resoluções do seu Conselho Gestor, órgão consultivo e deliberativo, composto de forma paritária pelos segmentos descritos na tabela 3 .

Tabela 3

Composição do Conselho Gestor do Fehis - estado da Bahia

\begin{tabular}{|lcr|}
\hline \multicolumn{1}{|c}{ Segmento } & Quantidade & $\%$ \\
\hline P. Público Federal & 3 & $8,8 \%$ \\
P. Público Estadual & 11 & $32,4 \%$ \\
P. Público Municipal & 2 & $5,9 \%$ \\
Movimentos Populares & 8 & $23,5 \%$ \\
Sindicatos dos Trabalhadores & 3 & $8,8 \%$ \\
Sindicato dos Empregadores & 3 & $8,8 \%$ \\
ONGs & 1 & $2,9 \%$ \\
Entidades Profissionais/ Pesquisa & 2 & $5,9 \%$ \\
Legislativo Estadual & 1 & $2,9 \%$ \\
\multicolumn{1}{|c}{ TOTAL } & 34 & $100,0 \%$ \\
\hline
\end{tabular}

Fonte: Bahia (2009).

A forma paritária de composição do conselho e a reserva de oito vagas para representantes dos movimentos populares e sociais demonstram, em tese, uma correlação de força favorável a este segmento. Entretanto, não é possível observar ações claras para estender essa paridade numérica a uma paridade substancial. Durante o período analisado, não foi verificada ação da Sedur que buscasse a capacitação ou apresentação de estudos técnicos que pudessem contribuir com os meios necessários ao exercício de suas competências, bem como se apropriar do funcionamento da burocracia pública.

Também é possível observar o esvaziamento e desqualificação dessa instância enquanto locus de partilha de poder. Pode-se constatar, através da análise das atas de reuniões referentes aos anos de 2009, 2010 e 2011, que, das oito reuniões convocadas pela Sedur, seis não foram realizadas em razão da falta de quórum. É possível imputar esse fato principalmente ao 
absenteísmo dos membros governamentais, podendo ser destacada a ausência dos representantes do Legislativo estadual em todas as reuniões do conselho e uma ausência quase absoluta dos representantes do poder público federal. Em relação aos membros do poder público estadual, em apenas uma reunião foi possível contar com a presença de sete representantes, dos 11 membros designados. Em todas as outras, esse número foi igual ou menor do que cinco, nos termos da tabela 4.

A recorrente falta de quórum mostra o reduzido valor atribuído a essa instância por setores do governo. Também é sintomática a ausência do secretário de Desenvolvimento Urbano, presidente do Conselho Gestor do Fehis, em todas as reuniões convocadas, sendo as suas atribuições assumidas pela vice-presidente do Conselho, no caso, a titular da Superintendência de Habitação. Em relação à participação da sociedade civil, é importante destacar que o segmento movimento popular foi o mais assíduo nas reuniões. Por outro lado, os representantes dos empregadores foi o segmento mais ausente no âmbito dos representantes da sociedade civil.

Tabela 4

\section{Reuniões Conselho Gestor do Fehis} Conselheiros presentes por segmento $(2009,2010,2011)$

\begin{tabular}{|c|c|c|c|c|c|c|c|c|c|c|c|c|c|c|c|c|}
\hline & \multicolumn{2}{|c|}{ 28-8-09 } & \multicolumn{2}{|c|}{ 24-11-09 } & \multicolumn{2}{|c|}{ 30-11-09 } & \multicolumn{2}{|c|}{$15-12-09$} & \multicolumn{2}{|c|}{$18-8-10$} & \multicolumn{2}{|c|}{$23-11-10$} & \multicolumn{2}{|c|}{$16-6-11$} & \multicolumn{2}{|c|}{$21-7-11$} \\
\hline & $\mathrm{n}^{\circ}$ & $\%$ & $\mathrm{n}^{\circ}$ & $\%$ & $\mathrm{n}^{\circ}$ & $\%$ & $\mathrm{n}^{\circ}$ & $\%$ & $\mathrm{n}^{\circ}$ & $\%$ & $\mathrm{n}^{\circ}$ & $\%$ & $\mathrm{n}^{\circ}$ & $\%$ & $\mathrm{n}^{\circ}$ & $\%$ \\
\hline P. Público Federal & 0 & $0,0 \%$ & 0 & $0,0 \%$ & 0 & $0,0 \%$ & 0 & $0,0 \%$ & 0 & $0,0 \%$ & 1 & $33,3 \%$ & 0 & $0,0 \%$ & 0 & $0,0 \%$ \\
\hline P. Público Estadual & 3 & $27,3 \%$ & 5 & $45,5 \%$ & 4 & $36,4 \%$ & 4 & $36,4 \%$ & 3 & $27,3 \%$ & 5 & $45,5 \%$ & 7 & $63,6 \%$ & 5 & $45,5 \%$ \\
\hline $\begin{array}{l}\text { Legislativo } \\
\text { Estadual }\end{array}$ & 0 & $0,0 \%$ & 0 & $0,0 \%$ & 0 & $0,0 \%$ & 0 & $0,0 \%$ & 0 & $0,0 \%$ & 0 & $0,0 \%$ & 0 & $0,0 \%$ & 0 & $0,0 \%$ \\
\hline $\begin{array}{l}\text { P. Público } \\
\text { Municipal }\end{array}$ & 1 & $50,0 \%$ & 0 & $0,0 \%$ & 1 & $50,0 \%$ & 0 & $0,0 \%$ & 1 & $50,0 \%$ & 1 & $50,0 \%$ & 0 & $0,0 \%$ & 0 & $0,0 \%$ \\
\hline $\begin{array}{l}\text { Movimentos } \\
\text { Populares }\end{array}$ & 6 & $75,0 \%$ & 7 & $87,5 \%$ & 3 & $37,5 \%$ & 7 & $87,5 \%$ & 6 & $75,0 \%$ & 3 & $37,5 \%$ & 8 & $100,0 \%$ & 2 & $25,0 \%$ \\
\hline $\begin{array}{l}\text { Sindicatos dos } \\
\text { Trabalhadores }\end{array}$ & 1 & $33,3 \%$ & 1 & $33,3 \%$ & 1 & $33,3 \%$ & 3 & $100,0 \%$ & 1 & $33,3 \%$ & 1 & $33,3 \%$ & 1 & $33,3 \%$ & 0 & $0,0 \%$ \\
\hline ONGs & 0 & $0,0 \%$ & 1 & $100,0 \%$ & 0 & $0,0 \%$ & 1 & $100,0 \%$ & 1 & $100,0 \%$ & 1 & $100,0 \%$ & 1 & $100,0 \%$ & 1 & $100,0 \%$ \\
\hline $\begin{array}{l}\text { Entidades } \\
\text { Profissionais/ } \\
\text { Pesquisa }\end{array}$ & 0 & $0,0 \%$ & 2 & $100,0 \%$ & 2 & $100,0 \%$ & 1 & $50,0 \%$ & 1 & $50,0 \%$ & 2 & $100,0 \%$ & 1 & $50,0 \%$ & 1 & $50,0 \%$ \\
\hline $\begin{array}{l}\text { Sindicato dos } \\
\text { Empregadores }\end{array}$ & 0 & $0,0 \%$ & 2 & $66,7 \%$ & 0 & $0,0 \%$ & 0 & $0,0 \%$ & 3 & $100,0 \%$ & 0 & $0,0 \%$ & 0 & $0,0 \%$ & 1 & $33,3 \%$ \\
\hline TOTAL & 11 & & 18 & & 11 & & 16 & & 16 & & 14 & & 18 & & 10 & \\
\hline
\end{tabular}

Fonte: Bahia (2009) e Atas das Reuniões do Conselho Gestor do Fehis. 
A situação ainda é mais grave quando se passa à análise dos recursos destinados ao Fehis. O único recurso efetivamente destinado ao Fundo foi repassado na oportunidade da sua regulamentação. Em 2009, foram destinados R 8.195.221,00 oriundos do Fundo de Compensação de Variações Salariais, decorrentes do processo de liquidação da Habitação e Urbanização da Bahia S.A. e Banco do Estado da Bahia.

É importante observar que essa omissão do poder público na destinação de recursos ao Fundo Estadual de Interesse Social não está lastreada na falta de previsão orçamentária para habitação de interesse social, visto que foram previstos nos anos de 2009, 2010 e 2011, respectivamente, 102 milhões, 98 milhões e 223 milhões para habitação (Bahia, 2012). Esses recursos foram executados diretamente pela Sedur e descentralizados para cooperativas e associações sem fins lucrativos que atuam na área de habitação, órgãos da administração pública municipal e Conder, empresa pública da administração indireta vinculada à Sedur atingindo, segundo informam relatórios governamentais (Bahia, 2012), nos anos de 2009, 2010, 2011, respectivamente 31,78\%, 64,98\% e 43,98\% de execução financeira.

Ademais, a maior fonte de recursos do orçamento geral do estado da Bahia destinados à habitação provém do Fundo Estadual de Combate e Erradicação da Pobreza, criado pela Lei Estadual no 7.988, de 21 de dezembro de 2001, que prevê a aplicação de recursos em ação de nutrição, habitação, educação, saúde, reforço da renda familiar (Bahia, 2001). Nos anos de 2009, 2010 e 2011 foram executados no âmbito da habitação de interesse social, respectivamente, 13 milhões, 30 milhões e 54 milhões oriundos dessa fonte (Bahia, 2012).

O Fundo Estadual de Combate e Erradicação da Pobreza está vinculado à Casa Civil, concentrando forte componente de poder decisório na figura do governador do estado, visto que, embora esse fundo tenha sua programação estabelecida pelo Conselho de Políticas de Inclusão Social, possui um arranjo institucional extremamente desfavorável à sociedade civil, notadamente aos setores vinculados aos movimentos de luta pela moradia. É um conselho de caráter meramente consultivo, composto por oito membros do poder público estadual e apenas três representantes da sociedade civil organizada, escolhidos entre os representantes da sociedade civil no Conselho Estadual dos Direitos da Criança e do Adolescente, Conselho Estadual de Assistência Social, Conselho Estadual de Saúde, Conselho das Voluntárias Sociais, Conselho das Igrejas Cristãs e Conselho de Desenvolvimento da Comunidade Negra.

A desvinculação entre investimento público em habitação de interesse social e os mecanismos de planejamento e controle social previstos no SNHIS não põe em dúvida apenas o alcance da democracia participativa no estado da Bahia. No plano nacional, grande parte da produção habitacional é operada por fora do SNHIS, através do Programa Minha Casa Minha Vida (PMCMV), cuja concepção foi gestada no âmbito da Casa Civil do governo federal, sem a participação do Conselho Nacional das Cidades. Entre o período de julho de 2009 a junho de 2013, a Caixa Econômica Federal contratou, no Brasil, 2.783.275 unidades habitacionais, sendo concluídas e entregues 1.247.859, através do PMCMV (Bahia, 2013).

Em meio às restrições expostas ao exercício da democracia, é possível apontar, no âmbito do Conselho Estadual das Cidades, alguns avanços que, longe de macular a constatação dos seus limites, contribuem para evidenciar a necessidade de uma maior aproximação do 
exercício da cidadania institucionalizada com a "cidadania insurgente" (Holston, 2008). A Resolução no 3/2009 do Conselho Estadual das Cidades, que estabelece os critérios e percentuais para acesso ao PMCMV, garantiu que 60\% das unidades construídas em projetos que envolvem contrapartida do estado fossem destinadas a famílias residentes em ocupações coletivas, demonstrando, em tese, uma força vinculada àqueles que efetivamente constroem a cidade no seu cotidiano. Esse dado ganha ainda mais relevância se observado que foram inscritas no PMCMV 394.333 pessoas, sendo 376.886 relacionadas a demandas habitacionais isoladas por família e 17.447 enquadradas na hipótese de "residente em ocupação coletiva".

Essa aparente vitória do movimento social de luta pela moradia não pode deixar de ser analisada com maior acuidade. A Resolução no 3/2009 traz em si algumas ambiguidades. A partir das atas de reuniões do Conselho Estadual da Cidade, é possível advertir que o horizonte aberto pelo PMCMV para aquisição da casa própria tendeu a direcionar as discussões para quotas, cadastros e critérios para aquisição das unidades habitacionais do Programa, fragilizando, em alguns momentos, as reivindicações do movimento social de luta pela moradia direcionadas à garantia do direito à cidade. Em muitos casos, a possibilidade de aquisição da casa própria, somada à iminência de despejos forçados, respaldados em liminares deferidas nas ações de reintegração de posse, levou os ocupantes de prédios públicos e privados, localizados no Centro Antigo de Salvador, a "optarem" pela remoção para unidades do PMCMV localizadas em áreas não centrais (Bahia, 2010).

A conquista do direito à cidade também ficou ameaçada em função da qualidade dos seus projetos arquitetônicos e da localização dos conjuntos habitacionais (Maricato, 2011; Rolnik e Nakano, 2009; Cardoso et al., 2013). O processo de contratação, centralizado pela Casa Civil do governo do Estado, em muitos momentos, desconsiderou as diretrizes da Pehis, subordinando a qualidade dos projetos ao cumprimento das metas da Caixa Econômica Federal e à pressão dos setores empresariais.

\section{Considerações finais}

A ambiguidade dos processos democráticos e o exercício de pôr em prática uma concepção de democracia participativa impulsionam uma avaliação dialética dos seus pontos de estrangulamento. Embora seja forçoso reconhecer que se trata de uma prática ainda recente impedindo análises conclusivas, já é possível apontar alguns elementos que enfraquecem a construção de uma concepção democrática de cunho substantivo e redistributivo.

O processo de construção e implementação da Pehis apresenta-se alinhado a princípios e diretrizes da democracia participativa, como aqui conceituada, em muitas das dimensões que inscreve: abertura de canais permanentes de discussão e pactuação de propostas e projetos, incorporação de instâncias jurídicas de garantia de direitos, incorporação da dimensão ambiental, mediação de conflitos fundiários, entre outras. Contudo, é possível observar a complexidade da dinâmica estatal através do conflito de agendas dentro do próprio governo. Se, por um lado, havia proposições no sentido de fortalecer os princípios, diretrizes e instru- 
mentos historicamente construídos, baseados nos pilares da luta pela reforma urbana, por outro lado, o pragmatismo na execução voltada para governabilidade limitou os avanços da prática democrática.

Esse balanço impõe uma reflexão e retorno do olhar para as subjetividades que guiaram a construção da luta pelo direito à cidade e dos processos participativos daí deflagrados. Por mais paradoxal que pareça, é justamente a partir da negação do direito a ter direito que insurgiu a construção da cidadania, nutrindo as subjetividades dos "não cidadãos" que, ao contestarem a sua exclusão, canalizam a reivindicação do direito à cidade. É nesse campo que transborda, através do processo de produção e reprodução da vida urbana, uma "cidadania insurgente" (Holston, 2008).

A abertura de espaços institucionais nos quais podem confluir essas insurgências é, sem dúvida, um avanço no processo de democratização da sociedade brasileira. Contudo, evidentemente não tem o condão de promover uma ruptura com os processos historicamente construídos e pautados numa cultura política baseada no clientelismo, autoritarismo e falta de transparência, que marcam os meandros da burocracia pública brasileira, demonstrando a necessidade de consolidação de uma democracia pela afirmação e universalização de direitos.

Se, por um lado, a articulação entre a democracia representativa e participativa possibilitou evidenciar a multiplicidade dos sujeitos coletivos que compõem a cena política brasileira, por outro, a proliferação desses espaços também aponta para um processo de pacificação dos conflitos sociais, o que tende a contribuir para dissipar seu potencial emancipatório. Nesse sentido, é preciso estar alerta para a condução da política nessas esferas públicas, visto que o pragmatismo que lastreia o processo de governabilidade vem paulatinamente buscando a construção de uma convergência em torno de projeto único e consensual que tende a erradicar os conflitos e antagonismos, o que, em última instância, aniquila a essência do espírito democrático, visto que, segundo Mouffe (2007), a sociedade democrática é aquela que possui esferas públicas vibrantes onde muitas visões conflitantes podem se expressar.

É possível perceber ainda que as sinergias foram paulatinamente canalizadas à regulação da ação pública e privada sobre a produção da cidade, sendo construídos marcos normativos para conceber uma roupagem legal às políticas setoriais de desenvolvimento urbano e ambiental. Apesar desse avanço, em muitos casos, a aplicação desses instrumentos está condicionada à criação de novos procedimentos jurídico-normativos na esfera local, impossibilitando uma superação real e efetiva da exclusão socioespacial e da produção corporativa da cidade, colocando em xeque a moldura institucional democrática do estado de direito. Essa aparente descentralização também não foi precedida de uma real repactuação federativa, calcada no princípio da igualdade e cooperação entre os entes federados.

\section{Referências}

ARRETCHE, Marta (Coord.). Capacidades administrativas dos municípios brasileiros para a política habitacional. Brasília: Cebrap/Centro de Estudo da Metrópole, 2012. 
AVRITZER, Leonardo. Conferências nacionais: ampliando e redefinindo os padrões de participação social no Brasil. Texto para discussão 1739, IPEA, Brasília, 2012. v. 1, p. 7-24 Disponível em: <http://repositorio.ipea.gov.br>. Acesso em: 27 fev. 2014.

AVRITZER, Leonardo. Modelos de deliberação democrática: uma análise do orçamento participativo no Brasil. In: SANTOS, Boaventura de S. (Org.). Democratizar a democracia: os caminhos da democracia participativa. Rio de Janeiro: Civilização Brasileira, 2002. p. 561-598.

BAHIA. Decreto no 11.539, de 15 de maio de 2009. Regulamenta o Fundo Estadual de Habitação de Interesse Social (Fehis) e o Conselho Gestor do Fehis criados pela Lei Estadual no 11.041, de 7 de maio de 2008, e dá outras providências. Diário Oficial do Estado da Bahia, Bahia, 16 maio 2009a. Disponível em: <www.legilabahia.gov.br>. Acesso em: 20 maio 2010.

BAHIA. Decreto Estadual no 10.366, de 4 de maio de 2007. Cria o Grupo de Trabalho para acompanhamento e sistematização da discussão e elaboração do anteprojeto da Lei da Política Estadual de Habitação de Interesse Social. Diário Oficial do Estado da Bahia, 4 maio 2007c. Disponível em: $<$ www.legilabahia.gov.br>. Acesso em: 20 maio 2010.

BAHIA. Decreto Simples. Designa os membros para compor o Grupo de Trabalho criado pelo Decreto no 10.366, de 31 de maio de 2007, que acompanhará e sistematizará a discussão e a elaboração do anteprojeto de lei da Política Estadual de Habitação de Interesse Social. Diário Oficial do Estado da Bahia, 20 jun. 2007b. Disponível em: <www.legilabahia.gov.br>. Acesso em: 20 maio 2010.

BAHIA. Lei Estadual no 7.988, de 21 de dezembro de 2001. Cria a Secretaria de Combate à Pobreza e às Desigualdades Sociais e o Fundo Estadual de Combate e Erradicação da Pobreza e dá outras providências. Diário Oficial do Estado da Bahia, 22 dez. 2001. Disponível em: <www.legilabahia. gov.br>. Acesso em: 20 maio 2010.

BAHIA. Lei Estadual no 11.041, de 07 de maio de 2008. Institui a Política e o Sistema Estadual de Habitação de Interesse Social, cria o Fundo Estadual de Habitação de Interesse Social e dá outras providências. Diário Oficial do Estado da Bahia, Bahia, 8 maio 2008. Disponível em: <www.legilabahia.gov.br>. Acesso em: 20 maio 2010.

BAHIA. Portaria no 43, de 20 de junho de 2007. Dá publicidade ao Regimento Interno que dispõe sobre os procedimentos e condução das audiências públicas da Política Estadual de Habitação de Interesse Social com abrangência nos territórios de identidade. Diário Oficial do Estado da Bahia, 21 jun. 2007a. Disponível em: <www.legilabahia.gov.br>. Acesso em: 20 maio 2010.

BAHIA. SEDUR. Diretoria de Regularização Fundiária. Relatório de atividades: 2007-2010. Salvador, 2010.

BAHIA. SEDUR. Minha Casa Minha Vida: viabilidade e sustentabilidade. Salvador, 2013.

BAHIA. SEDUR. Notas Política de Habitação de Interesse Social: panorama fundiário. Salvador: FEA, maio 2006a.

BAHIA. SEDUR. Notas técnicas elaboração da Política de Habitação de Interesse Social: documento síntese. Salvador: FEA, out. 2006. 
BAHIA. SEDUR. Portaria no 44, de 21 de junho de 2007. Convoca as audiências públicas para a discussão do Anteprojeto de Lei que cria o Conselho Estadual das Cidades da Bahia e do Anteprojeto de Lei que institui a Política Estadual de Habitação de Interesse Social (Pehis) e dá outras providências. Diário Oficial do Estado da Bahia, 22 jun. 2007. Disponível em: <www.legilabahia. gov.br>. Acesso em: 20 maio 2010.

BAHIA. SEDUR. Portaria no 63, de 28 de julho de 2009. Designa os representantes indicados pelos órgãos e entidades para compor o Conselho Gestor do Fundo Estadual de Habitação de Interesse Social (CGFEHIS). Diário Oficial do Estado da Bahia, Bahia, 31 jun. 2009. Disponível em: <www. legilabahia.gov.br>. Acesso em: 20 maio 2010.

BAHIA. SEDUR. Relatório consolidado de atividades, dos demonstrativos da execução orçamentária e dos elementos informativos e de controle. Salvador, 2012.

BITOUN, Jan. Movimentos sociais urbanos e a trajetória do urbanismo. Revista Cidades, São Paulo, v. 1, n. 1, p. 67-77, 2010.

BOBBIO, Norberto. O futuro da democracia: uma defesa das regras do jogo. 6. ed. Rio de Janeiro: Paz e Terra, 1986.

BRASIL. Lei no 10.257, de 10 de julho de 2001. Regulamenta os arts. 182 e 183 da Constituição Federal, estabelece diretrizes gerais da política urbana e dá outras providências. Diário Oficial da União, Brasília, 11 jul. 2001. Disponível em: <www.presidenciadarepublica.org.br>. Acesso em: ago. 2001.

BRASIL. Lei Federal no 11.124, de 16 de junho de 2005. Dispõe sobre o Sistema Nacional de Habitação de Interesse Social — SNHIS, cria o Fundo Nacional de Habitação de Interesse Social — FNHIS e institui o Conselho Gestor do FNHIS. Diário Oficial da União, Brasília, 17 jun. 2005. Disponível em: <www.presidenciadarepublica>. Acesso em: 10 out. 2005.

BRASIL. Ministério das Cidades, Secretaria Nacional da Habitação. Caderno Habitação. Política Nacional de Habitação. Brasília, 2004. Disponível em: <www.cidades.gov.br/secretarias-nacionais/ secretaria-de-habitacao/politica-nacional-de-habitacao/4PoliticaNacional Habitacao.pdf > . Acesso em: 21 ago. 2010.

BRASIL. Secretaria Nacional de Articulação Social. Conselhos e conferências. Brasília, 2014. Disponível em: <www.secretariageral.gov.br/art_social/conselhos-e-conferencias>. Acesso em: 20 fev. 2014.

CARDOSO, Adauto Lúcio et al. Quando um direito vira produto: impactos do Programa Minha Casa Minha Vida na Cidade do Rio de Janeiro. In: SIMPÓSIO NACIONAL DE GEOGRAFIA URBANA, XIII, 2013, Rio de Janeiro. Disponível em: <www.simpurb2013.com.br>. Acesso em: 15 fev. 2014.

CHAUÍ, Marilena. Cultura e democracia: um discurso competente e outras falas. 6. ed. São Paulo: Cortez, 1993.

DAGNINO, Evelina; OLVERA, Alberto; PANFICHI, Aldo. A disputa pela construção democrática na América Latina. São Paulo: Paz e Terra, 2006.

FLEURY, Sônia. A questão democrática na saúde. In: FLEURY, Sônia (Org.). Saúde e democracia: a luta da Cebes. São Paulo: Lemos, 1997. p. 25-41. 
FUNDAÇÃO JOÃO PINHEIRO. Centro de Estatística e Informações. Déficit habitacional municipal no Brasil. Belo Horizonte, 2013. Disponível em: <www.fjp.mg.gov.br>. Acesso em: fev. 2014.

GONH, Maria da Glória. Conselhos gestores e participação sociopolítica. 4. ed. São Paulo: Cortez, 2011. (Questões da nossa época. v. 32).

GONH, Maria da Glória. Novas teorias dos movimentos sociais. 4. ed. São Paulo: Loyola, 2012.

GRAZIA, Grazia de. Estatuto da cidade: uma longa história com vitórias e derrotas. In: OSÓRIO, Letícia, M. Estatuto da cidade e reforma urbana: novas perspectivas para as cidades brasileiras. Porto Alegre: Safe, 2002. p. 15-37.

HARVEY, David. Rebel cities: from the right to the city to the urban revolution. Londres; Nova York: Verso, 2012.

HOLSTON, James. Insurgent citizenship. Princeton: Princeton University Press, 2008.

IBGE. Instituto Brasileiro de Geografia e Estatística. Diretoria de pesquisa, coordenação de população e indicadores sociais. Pesquisa de Informações Básicas Municipais, 2012. Rio de Janeiro: IBGE. Disponível em: <ftp://ftp.ibge.gov.br/Perfil_Municipios/2011/munic2011.pdf>. Acesso em: 27 fev. 2014.

IBGE. Instituto Brasileiro de Geografia e Estatística. Pesquisa de Informações Básicas Municipais, 2009. Rio de Janeiro: IBGE. Disponível em: <www.ibge.gov.br/home/estatistica/economia/ perfilmunic/2009/munic2009.pdf>. Acesso em: 27 fev. 2014.

IPEA. Instituto de Pesquisa e Economia Aplicada. Conselhos Nacionais: perfil e atuação dos conselheiros. Relatório de Pesquisa, IPEA, Brasília, 2013. Disponível em: <www.ipea.gov.br/participacao/ images/pdfs/relatoriofinal_perfil_conselhosnacionais.pdfA >. Acesso em: 23 fev. 2014.

LEFEBVRE, Henri. O direito à cidade. São Paulo: Moraes, 1991.

MAGALHÃES, Inês. Apresentação. In: ARRETCHE, Marta (Coord.). Capacidades administrativas dos municípios brasileiros para a política habitacional. Brasília: Cebrap; Centro de Estudo da Metrópole, 2012.

MARICATO, Ermínia. Dossiê: Conferências Nacionais - uma política urbana participativa. Teoria e Debate, n. 66, abr./maio 2006. Disponível em: <http://csbh.fpabramo.org.br/>. Acesso em: 13 jan. 2013.

MARICATO, Ermínia. O impasse da política urbana no Brasil. In: MARICATO, Ermínia. O impasse da política urbana no Brasil. Petrópolis: Vozes, 2011. p. 15-88.

MOUFFE, Chantal. En torno a lo político. Buenos Aires: Fondo de Cultura Económica, 2007.

POLIS/INESC. Projeto de Pesquisa Governança Democrática no Brasil Contemporâneo: Estado e sociedade na construção de políticas públicas: a arquitetura da participação no Brasil: avanços e desafios. Relatório Final. Polis/Inesc, São Paulo, 2011. Disponível em: <www.polis.org.br>. Acesso em: 28 fev. 2014. 
PONTUAL, Pedro. Desafios à construção da democracia participativa no Brasil: a prática dos conselhos de gestão das políticas públicas. Coleção Cadernos da CIDADE, São Paulo, v. 12, n. 14, p. 27, nov. 2008.

ROLNIK, Raquel; NAKANO, Kazuo. As armadilhas do pacote habitacional. Le Monde Diplomatique, São Paulo, n. 20, p. 4-5, 2 mar. 2009.

SAFATLE, Wladimir. Amar uma ideia. In: HARVEY, David et al. Occupy. São Paulo: Boitempo; Carta Maior, 2012. p. 45-55.

SINTOMER, Yves et al. Diálogo global: apreendendo com o Sul, orçamento participativo no mundo: um convite à cooperação global. n. 25. Alemanha, Engagement Global, 2012. Disponível em: <www. ces.uc.pt/myces/UserFiles/livros/1097_DialogoGlobal_25pt.pdf>. Acesso em: 13 jan. 2013.

SOUSA SANTOS, Boaventura; AVRITZER, Leonardo. Para ampliar o cânone democrático. In: SOUSA SANTOS, Boaventura. (Org.). Democratizar a democracia: os caminhos da democracia participativa. Rio de Janeiro: Civilização Brasileira, 2002. p. 39-83.

SOUZA, Clóvis H. L. de et al. Conferências típicas e atípicas: um esforço de caracterização do fenômeno político. In: AVRITZER, Leonardo; SOUZA, Clóvis Henrique L. de. (Org.). Conferências Nacionais: atores, dinâmicas participativas e efetividade. Brasília: Ipea, 2013. p. 25-57.

TATAGIBA, Luciana. Os conselhos gestores e a democratização das políticas públicas no Brasil. In: DAGNINO, Evangelina (Org.). Sociedade civil e espaços públicos no Brasil. São Paulo: Paz e Terra, 2002. p. 47-105.

TORRES, Paulo R. Terra e territorialidade nas áreas de fundos de pastos no Semiárido Baiano 1980-2010. Dissertação (mestrado em planejamento social e desenvolvimento social) — Faculdade Católica, Salvador, 2011.

TREVAS, Vicente C. P. Consórcios públicos, uma aposta estratégica do federalismo brasileiro? Le Monde Diplomatique Brasil, São Paulo, p. 4-5, ago. 2012.

Adriana Nogueira Vieira Lima é doutoranda em arquitetura e urbanismo da Universidade Federal da Bahia (Ufba) e professora de direito urbanístico da Universidade Estadual de Feira de Santana. E-mail: adriananvlima@gmail.com. 